\title{
Spectral Depths Estimate of Subsurface Structures in Parts of Borno Basin, Northeastern Nigeria, using Aeromagnetic Data
}

\author{
Ajana O. ${ }^{1}$, Udensi E.E. ${ }^{2}$, Momoh M. ${ }^{1}$, Rai J.K. ${ }^{3}$ and Muhammad S.B. ${ }^{1}$ \\ ${ }^{1}$ Department of Physics, Usmanu Danfodiyo University Sokoto, Sokoto State, Nigeria \\ ${ }^{2}$ Department of Physics/Geophysics, Federal University of Technology Minna, Niger state, Nigeria \\ ${ }^{3}$ Department of Physics, Kebbi State University of Science and Technology Aliero, Kebbi State, Nigeria
}

\begin{abstract}
Spectral depth analysis of aeromagnetic data covering latitude $12.00^{\prime} \mathrm{N}$ to $13.00^{\prime} \mathrm{N}$ and longitude $10.00^{\prime}$ E to 11.00'E which corresponds to part of Borno basin, Northeastern Nigeria, was carried out for the purpose of investigating the sedimentary thickness beneath the surface. The study area was covered by 4 aeromagnetic maps. The aeromagnetic maps were digitized on a $3 \mathrm{~km}$ grid and later complied to produce a combined aeromagnetic data file for the area. The data file comprises 1369 data points. Polynomial fittings method was applied in the regional residual separation. The residual map was later sub-divided into 16 spectral sectors. The result of the study shows that the first layer depth was estimated to have a range from $0.18 \mathrm{~km}$ to about $1.9 \mathrm{~km}$ while the second layer depth was estimated to have ranged from $2.9 \mathrm{~km}$ to about $4.2 \mathrm{~km}$. The highest sedimentary thickness of $4.2 \mathrm{~km}$ occurred at the extreme northeast part of the study area and corresponds to areas around Gorgoram. These areas may be subjected for further geophysical method like seismic reflection/refraction, so as to ascertain its hydrocarbon potential.
\end{abstract}

Keywords: Aeromagnetic data, spectral, depth, sedimentary depth, first and second layer depth

\section{Introduction}

The Borno Basin Nigeria, in Northeastern Nigeria is part of the Chad basin, which extends into parts of Niger, Chad, Central African Republic (C.A.R) and Cameroon [1]. For almost three decades now researchers and scholars on petroleum potentials in Nigeria have concentrated in the south (Niger Delta and Anambra Basins), and recently in Benue tough, while little geophysical and geological works have been carried out in the Nigerian Chad basin in the North. The Nigerian Government has on its own demonstrated renewed efforts in the search for hydrocarbon accumulation in the basic in order to increase its oil and gas reserve base. This has, however, not been successful as no oil or gas has been discovered in a commercial quantity in the region. However, efforts are still on and more money is still being sunk into the area with the hope of finding oil in commercial quantity in the near future. This study will be very useful on a reconnaissance basis for oil and mineral prospecting in the area.

The spectral analysis of aeromagnetic fields over the area would differentiate and characterize regions of sedimentary thickness from those of uplifted or shallow basement and also to determine the depth to the magnetic sources. The results could be used to suggest whether or not the study area has the potential for oil/gas and mineral deposits concentration. This study area is bounded by latitude $12^{0} \mathrm{~N}$ to $13^{\circ} \mathrm{N}$ and longitude $10^{\circ} \mathrm{E}$ to $11^{0} \mathrm{E}$ located within the northern part of Borno Basin and covered by 4 aeromagnetic maps.

\section{Geology Of The Study Area}

The Chad Basin lies within a vast area of central and West Africa at an elevation of between 200 and $500 \mathrm{~m}$ above sea level and covering $\sim 230,00 \mathrm{~km}^{2}$. It is the largest area of inland drainage in Africa according to [2], [3], and [1]. It extends into parts of the republic of Niger, Chad, Cameroon, Nigeria and Central Africa. The Nigerian Chad Basin is about one tenth of the basin [4], [5]. Information on the geology of the Nigeria sector of the basin is scarce. However, the recent advancement in the exploration campaign by the Nigerian National Petroleum Corporation (NNPC) has revealed more data which formed the basis of the recent studies on the geology of the area. [6] Identified three major sediment packages - the Bima formation, gongila - Fika shale and the Chad formations in the Nigerian sector of the Chad basin. 


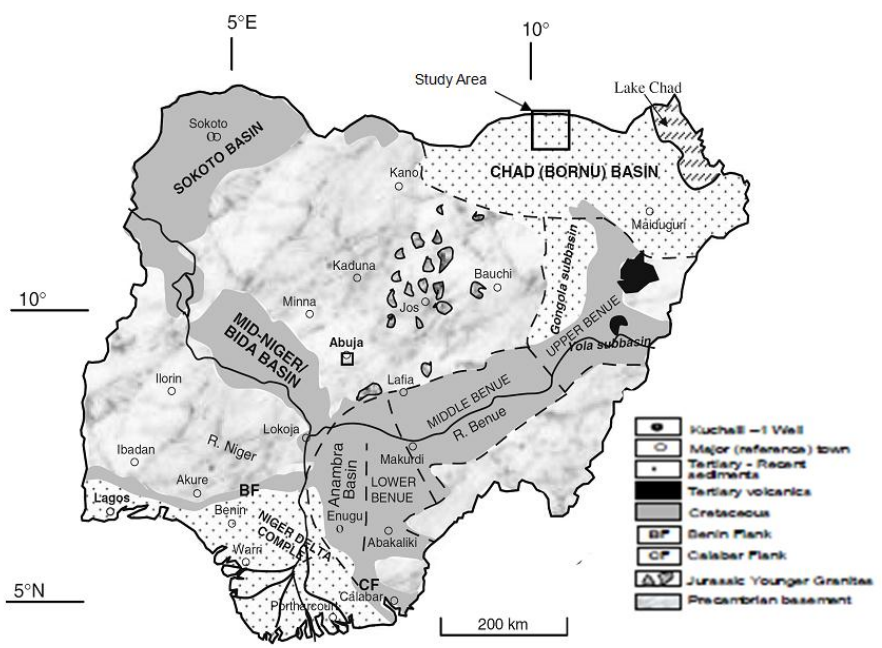

Figure1: General Geology map of Nigeria showing the location of the study area. Adopted from [7].

\section{Materials And Method}

The aeromagnetic dataset used for this study was obtained from the Nigerian Geological Survey Agency as a part of the nation - wide aeromagnetic survey between 1974 and 1980. The magnetic data were collected at a normal flight altitude of $154.2 \mathrm{~m}$ along approximately N-S flight lines spaced $2 \mathrm{~km}$ apart. The study area is covered by four aeromagnetic maps of total field intensity in $1 / 2^{0}$ by $1 / 2^{0}$ sheets on a scale of $1: 100,000$. The magnetic values were plotted at 10nT interval. The actual magnetic values were reduced by 25,000 gammas before plotting the contour maps. A correction based on the International Geomagnetic Reference Field, IGRF, dated January 1, 1974 was included in all the maps. The aeromagnetic maps were digitized along flight lines with a spacing of 500m and the intersection points were picked and contoured using software.

Digitalization of data is followed by separation of aeromagnetic data. Here, a linear trend surface was fitted on to the digitized aeromagnetic data by a multiple regression technique for the purpose of removing the regional magnetic gradient. The linear surface so fitted was removed from the digitized data so as to obtain the residual anomaly data which was used to construct residual anomaly map.

The data were then transformed into regular grid using computer software surfer 8 which carried out interpolation of data and contoured the anomalies (total magnetic intensity and residual).

The residual anomaly was subjected to spectral analysis. This method of analysis has been widely used by several authors $[8,9,10$, and 11] to determine the depths of magnetic anomalies.

Fig. 2 and 3 are the total magnetic intensity map of the study area and the residual magnetic map of the study area respectively.

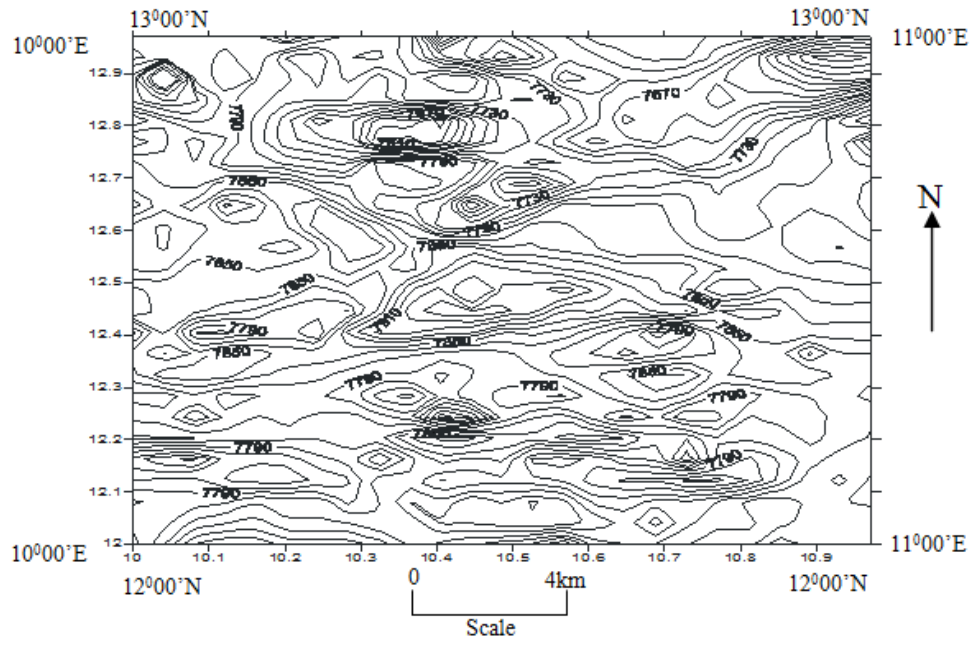

Figure 2: Total magnetic intensity map of the study area (contour interval 20nT). 


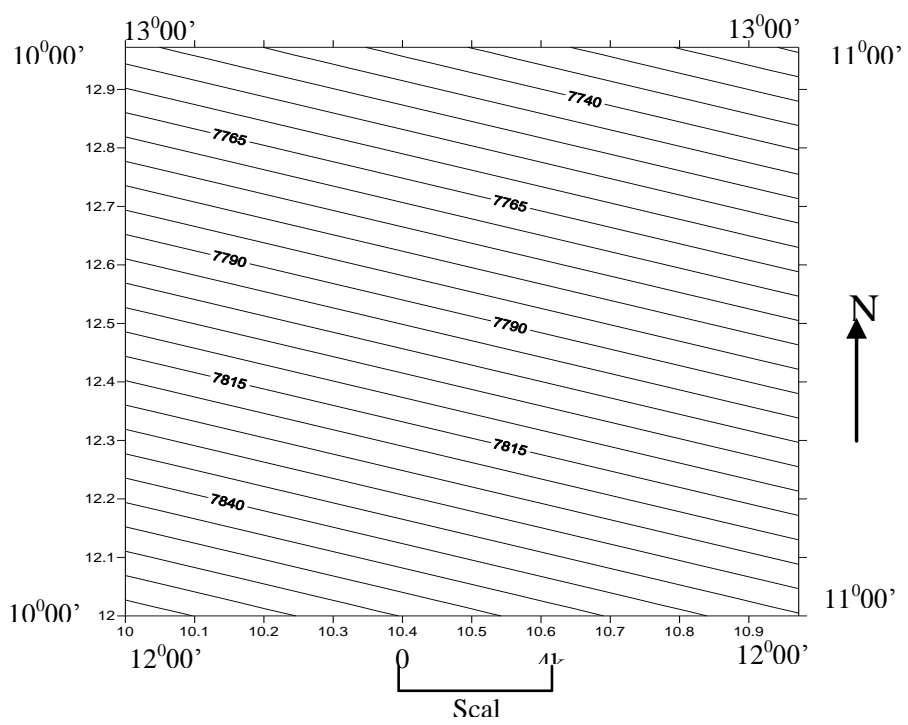

Figure 3: Residual anomaly map of the study area (contour interval 20nT).

\section{Spectral Analysis}

The spectral analysis of the residual field data was used to determine the depth to the buried magnetic sources within the subsurface of the study area. [6] developed a 2-D spectral depth determination method. Their model assumes that an uncorrelated distribution of magnetic sources exists at a number of depth intervals in a geological column. The Fourier transforms of the potential field due to a prismatic body has a broad spectrum whose peak location is a function of the depth to the top and bottom surface and whose amplitude is determined by its magnetization.

For a bottomless prism, the spectrum peak at the zero wave number according to the expression:

$$
F(\omega)=e^{-h \omega}
$$

Where $\omega$ is the angular wave number in radian/ground - unit and $\mathrm{h}$ is the depth to the top of the prism. For a prism with top and bottom surface, the spectrum is:

$$
F(\omega)=e^{-h_{t} \omega}-e^{-h_{b} \omega}
$$

Where $h_{t}$ and $h_{b}$ are the depths to the top and bottom surface respectively. As the prism bottom moves closer to the observation point at surface, the peak moves to a higher wave number. The effect of increasing the depth is to shift the peak to a lower wave number [8].

Because of these characteristics, there is no way to separate the effect of deep sources from shallow sources of the same type by using wave number filters. The sources can only be separated if the deep sources have greater amplitude or if the shallow sources have less depth extent [12]. When considering a line that is long enough to include many sources, the log spectrum of this data can be used to obtain the depth to the top of statistical ensembles of sources using the expression:

$$
\log E(k)=4 \pi h k
$$

Where $\mathrm{h}$ is the depth in ground - unit and $\mathrm{k}$ is the wave number in cycles/ground- unit. The depth of an ensemble of sources can be determined by measuring the slope of the energy (power) spectrum and dividing by $4 \pi$.

Computer software was used to generate the energy frequency plots and the slopes. From the slopes of the plot, the first and the second magnetic sources depth was respectively estimated using the expression:

$$
\begin{aligned}
& Z_{1}=-\frac{m_{1}}{4 \pi} \\
& Z_{2}=-\frac{m_{2}}{4 \pi}
\end{aligned}
$$

Where $m_{1}$ and $m_{2}$ are slopes of the first and second segments of the plots while $Z_{1}$ and $Z_{2}$ are first and second depths respectively (TABLE 1). Contour maps and surface plots of the first layer magnetic source $\left(Z_{1}\right)$ and second layer magnetic sources $\left(\mathrm{Z}_{2}\right)$ were also obtained using suffer 8 computer software. 


\section{Results}

Table 1 shows the estimated magnetic source for both the shallow sources (depth 1) and deeper sources (depth 2). Equation (4) and (5) shows the relationship between the depth (h) to the basement and the decay slop $(\mathrm{m})$ of the energy spectrum. The first layer depth $\left(Z_{1}\right)$ varies in thickness from $0.18 \mathrm{~km}$ minimum to $1.9 \mathrm{~km}$ maximum and the second layer depth $\left(\mathrm{Z}_{2}\right)$ varies in thickness from $2.9 \mathrm{~km}$ minimum to $4.2 \mathrm{~km}$ maximum. Theses depths are in conformity with the deductions of [1], [3], [13], [14], where depths of up to $5 \mathrm{~km}$ where subsequently proven from seismic refraction data. Fig. 4(a) shows the first layer $\mathrm{Z}_{1}$ depth contoured at an interval of $10 \mathrm{~m}$ vertical and horizontal axes. The contours are more concentrated at the Northwest part of the map. This is likely to subsurface magnetic materials. Fig. 4(b) shows the surface plot of the first magnetic layer. Fig. 5(a) show the second layer $Z_{2}$ depth contoured at an interval of $10 \mathrm{~m}$ vertical and horizontal axis. Fig. 5(b) shows the surface plot of the second magnetic layer. The layer dips towards the Northwest and has a minimum thickness of $2.9 \mathrm{~km}$ and a maximum thickness of $4.2 \mathrm{~km}$. This depth may be attributed to magnetic rocks that are emplaced or intruded into the basement underlying the sedimentary basin. Also, intra-basement features such as fractures could equally contribute to sources that accounted for the second layer depth. This depth thus represents a depth to the underlying magnetic basement rock within the study area which also represents the average thickness of the sedimentary pole within the study area.

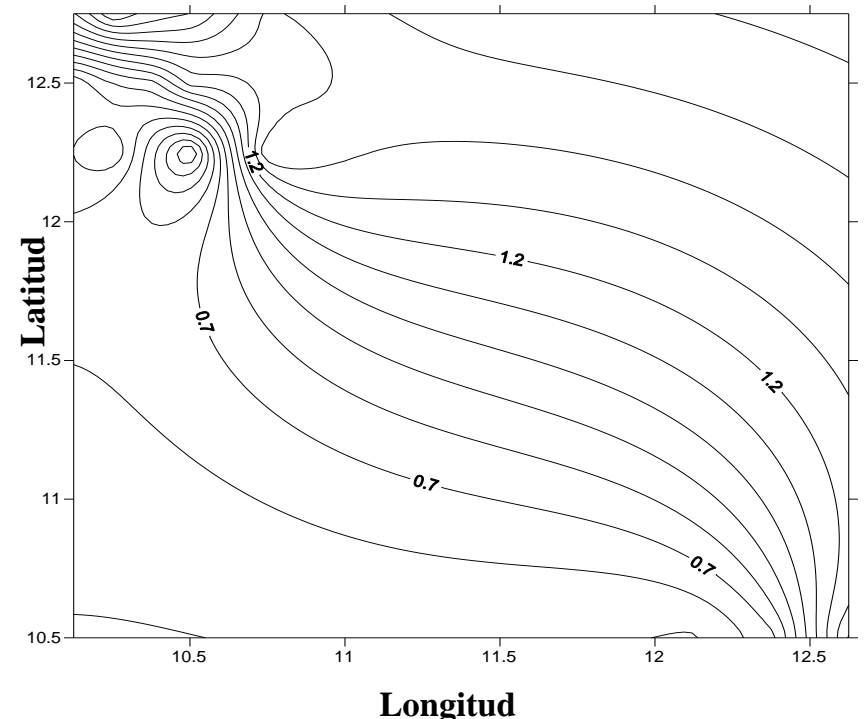

(a)

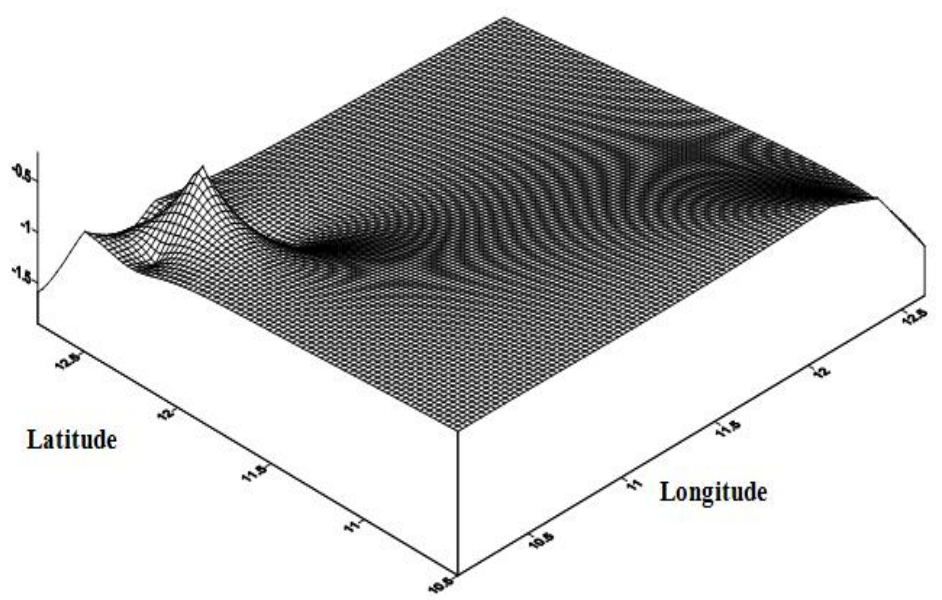

(b)

Figure 4: (a) Contour map of $1^{\text {st }}$ layer magnetic source. (b) Surface map of shallow magnetic source depth. 
Table 1: Estimated depth of the shallow (depth) magnetic sources in $\mathrm{Km}$

\begin{tabular}{lllll}
\hline Block & Longitude & Latitude & $\mathbf{Z}_{\mathbf{1}}(\mathbf{k m})$ & $\mathbf{Z}_{\mathbf{2}}(\mathbf{k m})$ \\
\hline 1 & 10.25 & 12.25 & 0.90 & 3.90 \\
2 & 10.75 & 12.25 & 1.50 & 3.50 \\
3 & 10.25 & 12.75 & 1.90 & 3.90 \\
4 & 10.50 & 12.75 & 1.38 & 4.50 \\
5 & 10.50 & 12.25 & 0.18 & 3.30 \\
6 & 10.50 & 12.75 & 1.70 & 4.20 \\
7 & 10.50 & 12.50 & 1.24 & 3.74 \\
8 & 10.25 & 12.50 & 0.90 & 3.40 \\
9 & 10.75 & 12.50 & 1.34 & 3.88 \\
10 & 10.13 & 12.50 & 0.71 & 3.25 \\
11 & 10.38 & 12.50 & 0.96 & 3.50 \\
12 & 10.63 & 12.50 & 1.26 & 3.80 \\
13 & 10.88 & 12.50 & 0.46 & 3.00 \\
14 & 10.63 & 12.50 & 0.66 & 3.20 \\
15 & 11.00 & 13.00 & 1.41 & 3.95 \\
\hline
\end{tabular}

(a)

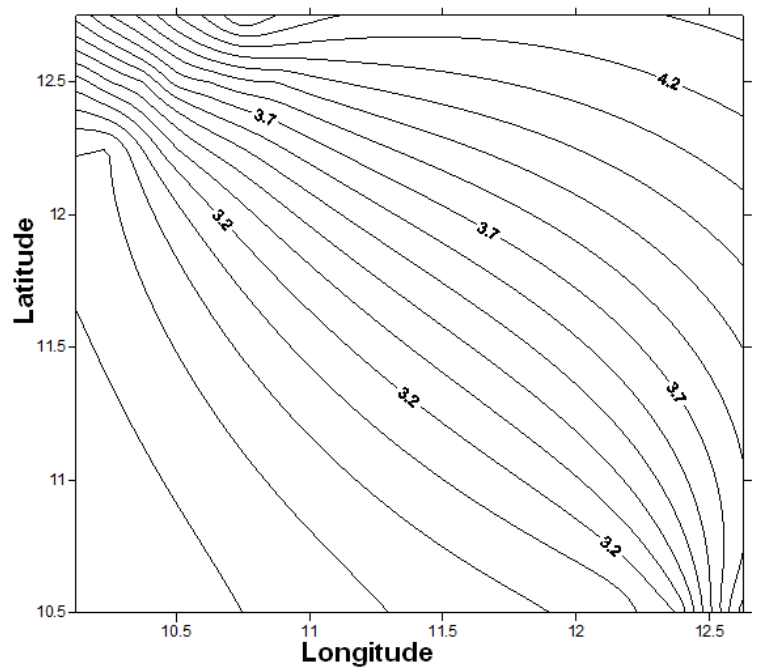

(a)

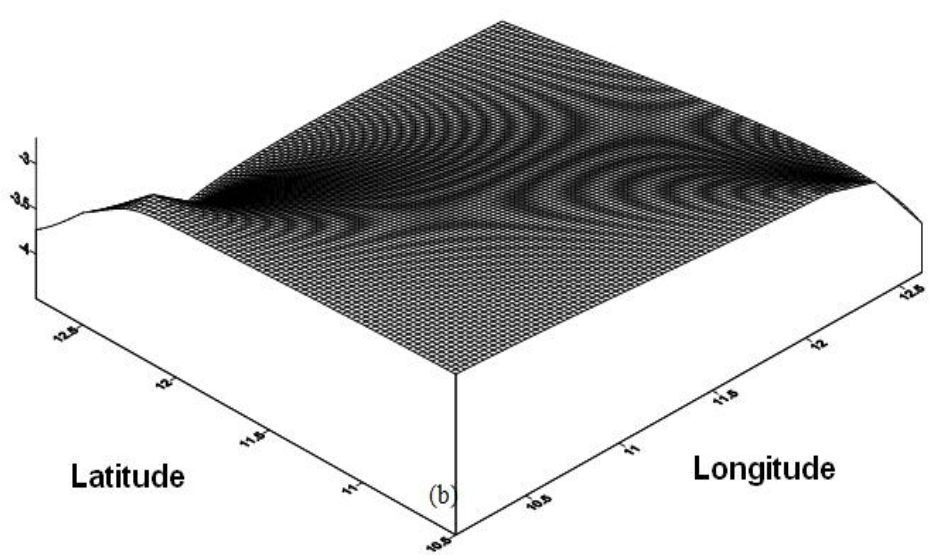

(b)

Figure 5: (a) Contour map of second layer magnetic source (b) Surface map of deeper magnetic source depth

\section{Conclusion}

Hydrocarbon presence and its potential is usually enhanced by the thickness of the sediment of the basin and also the kind of geological structures existing within the basement that form traps for oils and gas. The result revealed two major magnetic horizons under the area; the shallow magnetic sources represented by high frequency segment of the spectrum $\mathrm{Z}_{1}$, while the deeper magnetic sources are represented by low frequency segment of the spectrum $\mathrm{Z}_{2}$.

The highest sedimentary thickness obtained in the area with spectral analysis is $4.2 \mathrm{~km}$. This highest sedimentary thickness was found at the Northeastern part of the study area. This area of high sedimentary thickness should be the target for further exploration. 


\section{Reference}

[1] A.A. Avbovbo, E.O. Ayoola, and G.A. Osahon, Depositional and structural styles in Chad Basin of Northeastern Nigeria. Bulletin American Association Petroleum Geologists, 70(121), 1986, 1787 - 1798.

[2] W. Barber, Pressure water in the Chad formation of Bornu and Dikwa Emirates, NE Nigeria. Bulletin Geological Survey of Nigeria, No. 35, (1965), p.138.

[3] G. Matheis, Short review of the geology of chad basin in Nigeria, in C.A., Kogbe (2), Geology of Nigeria, (Lagos, Nigeria: Elizabethan Publication Company, 1976) 289-294.

[4] J.B. Wright, Origin of the benue trough- a critical review, in C.A., Kogbe (2), Geology of Nigeria, (Lagos, Nigeria: Elizabethan Publication Company, 1976) 309-317.

[5] J.D. Falconer, The geology and geography of northern Nigeria (London, UK: MacMillan, 1911).

[6] C.N. Nwankwo, A.S. Ekine, and L.I. Nwosu, Estimation of heat flow variation in the chad basin Nigeria, Journal of Applied Science and Environment, 13(1), 2009, $73-80$.

[7] N. Obaje, H. Wehner, G. Scheeder, M. Abubakar, and A. Jauro, Hydrocarbon prospectively of Nigeria's inland basins: from the viewpoint of organic geochemistry and organic petrology. AAPG bulletin, 88(3), 2004, 325 - 353.

[8] G. Spectra and F.S. Grant, Statistical Mode for Interpreting Aeromagnetic Data, Geophysics, 35(2), 1970,293 - 302.

[9] A.G. Onwuemesi, One dimensional spectral analysis of aeromagnetic anomalies and curie depthsotherm in the anambra basin of Nigeria, Journal of Geodynamics, 23(2), 1997, 95 - 107.

[10] Y.I. Abubakar, M.N. Umego and S.B. Ojo, Evaluation of gongola basin upper benue trough, northeastern Nigeria, Asia Journal of Earth Science, 3(1), 2010, $62-72$.

[11] E.K. Anakwuba, A.G. Onwuemesi, A.I. Chinwuko and L.N. Onuba, The interpretation of aeromagnetic anomalies over maiduguridikwa depression, chad basin Nigeria, Archives of Applied Science Research, 3(4), 2011, 499 - 508.

[12] K.A. Salako, E.E. Udensi, E.E., Spectral depth analysis of parts of upper benue trough and borno basin, north-east Nigeria, using aeromagnetic data, International Journal of Science and Research, 2 (8), 2013, 48 - 55.

[13] E.A. Okonsun, Review of the geology of bornu basin, Journal of mining and Geology, 31(2), 1955,113 - 172.

[14] N.G. Obaje, Geology and Mineral of Nigeria ( Germany: Springer Verlag, 2009). 